\title{
TRATAMENTO DO ACIDENTE VASCULAR CEREBRAL AGUDO
}

\author{
J.P. MOHR*-V. OLIVEIRA**
}

\begin{abstract}
RESUMO - Avanços tecnológicos recentes beneficiaram o diagnóstico do acidente vascular cerebral (AVC), reduziram os riscos e aumentaram a freqüência de cstudos acerca dos mecanismos do AVC. Projetos baseados em bancos de dados computadorizados trouxeram novas luzes quanto à freqủência de subtipos de AVC e aos riscos de sua progressão e recorrência. Elevada freqüència de AVC̈ devidos a infarto continua sem explicação, apesar de exaustiva investigaçăo laboratorial. Esses infartos de causa nåo determinada upresentam indices de recorrência quase tão elevados como no embolismo cardiogênico, forçando rápida decisão terapêutica, mesmo na ausência de causa demonstrada para eles. AVC devido a aterosclerose é menos comum do que se acreditava, mas traz consigo maior risco de piora $e$ de recorrência precoce, obrigando a adoçāo de tratamento precoce na tentativa de evitar sua progressão. Os nétơơs Doppler duplex e transcraniano de imagem de vasos e fluxo tornaram possivel atualmente seguir de modo não invasivo a evolução de estenose ateromatosa, embolismo e recanalização, desenvolvimento de circulaçāo colateral e, ainda, ocorrência de vasospasmo em aneurismas rotos e malfornıçōes arteriovenosas. Doença ateromatosa extracraniana pode progrediy rapidamente, passando a estenose de discreta a severa, podendo, no entanto, estabilizar-se em qualquer ponto da evolução. O grau de estenose extracraniana năo permite pressupor aquele de circulação colateral intracraniana. Recanalização ocorre precocemente no embolismo cerebral. Vasospasmo após hemorragia sub-aracnóidea é comum e, por vezes, severo. Sempre que possivel deve ser dada preferência à ressonância magnética, em lugar da tomografia computadorizada, para o diagnóstico de qualquer tipo de AvC. inclusive hemorrágico.
\end{abstract}

\section{Treatment of acute stroke}

SUMMARY - Recent advances in technology have improved stroke diagnosis, reduced the risks and increased the frequency of studies of stroke mechanism. Computer-assisted stroke data bank proiects have orovided new insights into the frequencies of stroke subtypes and the risks for progression and recurrence. A high frequency of strokes due to infarction remain unexplained despite thorough laboratory investigation. These infarcts of undetermined cause suffer recurrence rates almost as high as cardiogenic embolism, forcing a therapeutic decision even in the absence of a demonstrated cause. Stroke from atherosclerosis is far less common than formerly believed but carries the highest risk of worsening and early recurrence, prompting early treatment to attempt to avoid progression. Duplex and transcranial doppler methods of imaging blood vessels and insonating flow have now made it possible non-invasively to follow the course of atheromatous stenosis, embolism and recanalization, development of collateral flow, and vasospasm in ruptured aneurysms and arteriovenous malformations. Extracranial atheromatous disease may progress rapidly from mild to sevcre stenosis, stabilize at any point; intracranial collateral is not predicted by the degree of extracranial stenosis. Recanalization of cerebral embolism occurs early. Vasospasm after subarachnoid hemorrhage is common and often severe. Where available, magnetic resonance imaging is preferred to CT scanning for the diagnosis of every form of stroke including hemorrhage.

The New York Neurological Institute (NYNI), Columbia-Presbyterian Medical Center, New York City: * Sciarra Professor of Clinical Neurology: ** Research Fellow at NYNI, Interno de Neurologia do Hospital Santa Maria, Lisboa. 
Nos dias que correm, poucos neurologistas desejam tomar decisões no tratamento dos acidentes vasculares cerebrais (AVC) sem substancial apoio de meios complementares de diagnóstico. No entanto, poucas instituiçōes estão suficientemente equipadas com todo o armamentário de técnicas laboratoriais e, mesmo em alguns casos relativamente simples, a tecnologia falha ou fornece resultados dificilmente interpretáveis e o clínico necessita, então, de tomar decisões fundamentado apenas em bases clínicas. Este artigo foi escrito na perspectiva de integrar os aspectos das sindromes clinicas agudas de modo a estabelecer um plano terapêtico para o tratamento dos AVC em sua fase aguda.

\section{AVC AGUDO COM DÉFICIT NEUROLÓGICO MACIÇO}

Déficits maciços, que se instalam em poucas horas, raramente são acidentes isquêmicos transitórios (AIT) não sendo de esperar por isso melhoria rápida, o que implica em estabelecer o neurologista rapidamente seus planos terapêuticos.

Quando a apresentação clínica é a de um AVC sensitivomotor severo com perda completa de hemifunçăo e déficit concomitante de funções nervosas superiores, deve suspeitar-se de quatro situações possiveis. A primeira é o efeito de massa provocado por uma hemorragia epi ou subdural ou, em segundo lugar, hematoma do lobo temporal quando os aspectos principais de apresentaçăo se manifestam como se fosse massa extraparênquimatosa, comprimindo as estruturas centrais através da vala sílvica 29. A terceira é a oclusăo aguda da artéria carótida interna. A quarta è a hemorragia cerebelosa. Por outro lado, os procedimentos de urgência para o tratamento dos AVC graves parecem ser, embora bem intencionados, mal dirigidos e os resultados das terapêuticas heróicas com manitol, esteróides, anticoagulantes, coma metabólico e procedimentos nas unidades de cuidados intensivos, continuam bastante insatisfatórios, mesmo em 198737.

Uma história de traumatismo contribui para o diagnóstico de hemorragia intraparenquimatosa mas, uma vez atingida a delicada fase de coma, não existe qualquer fórmula clínica que determine qual o paciente que poderá se beneficiar com a terapêutica cirúrgica: mesmo alguns doentes sem motilidade ocular nem respiração espontânea, têm saido do hospital pelos seus próprios meios depois de uma pronta recuperação. Uma vez que a rotura de uma malformação arteriovenosa ou luma hemorragia subaracnóidea podem produzir o mesmo efeito, é boa tática proceder-se a estudo angiográfico pré-operatório sempre que haja tempo para tal. Os estudos tomográficos (ГАC), com ou sem contraste, em geral documentam apenas a hemorragia mas năo sưa causa $5.7,16$ O recurso da ressonância magnética nuclear ( $R M N$ ) pode substituir tanto a TAC como a angiografia 17, mas apenas se o doente permanecer suficientemente imóvel de modo a poder obter-se as imagens necessárias. A remoçăo de emergência de tais lesões torna-se mandatória, na perspectiva de prevenir lesöes isquêmicas irreversíveis devidas a compressão de estruturas profundas do sistema nervoso central.

A ociusão aguda da artéria carótida interna é raramente diagnosticada nos serviços de urgência, pois o paciente parece estar seguindo a evoluçăo típica de um AVC irreversivel 9,15,43,46. Vários estudos têm sido feitos com séries de doentes e, em alguns casos esporádicos foi verificada no pós-operatório recuperação dramática das funções comprometidas. Nenhum ensaio clínico foi até agora efetuado para esclarecer este ponto, isto devido principalmente à pouca freqüência da apresentação de tais casos e às dificuldades em encontrar casos sobreponiveis. Admite-se, em tais circunstàncias, que a situaçăo terá sido detectada nas primeiras horas, antes de a isquemia se ter transformado em enfarte estabelecido 23,24. Nossa casuística abrange numerosos casos de disseç̧ão, o que presumivelmenete levou ao estabelecimento de uma situação de déficit de perfusão antes de se ter desenvolvido circulação colateral adequada 43 .

As hemorragias cerebelosas constituem um caso especial, devido ao fato de nelas não existir síndrome de déficit motor unilateral e comprometimento sensitivo. Pelo contrário, o doente pode ser primeiramente rotulado como tendo sindrome de Menière ou labirintite $e$, mais tarde, como apresentando estupor ou coma de origem metabólica. A compressão do tronco cerebral pode ser revertida se a intervenção cirúrgica for executada dentro de uma hora a partir do estabelecimento do estado de coma 37. Mesmo a síndrome em que a motilidade ocular está abolida, com os olhos 
olhando em frente, pupilas na posiçăo mediana e não reativas, tem sido encontrada em casos de hemorragia cerebelosa mediana alta e, por isso, năo devem se refrear os esforços que levem ao diagnóstico e a intervenção cirúrgica.

\section{AVC AGUDO SUBMAXIMO}

Em face de AVC menos severos, as preocupaçōes são nitidamente diferentes e o objetivo da terapèutica modifica-se consideravelmente. O primeiro objetivo é chegar-se a um diagnóstico do subtipo de AVC 19,32,51. O segundo, é a seleção das investigações laboratoriais a empreender para complementar a avaliação clínica do AVC. O objetivo da terapêutica é tentar estabilizar a evolução do processo ou, caso falhem tais objetivos, evitar a recorrência ou a sua progressão.

\section{SUBTIPOS DE AVC}

As fórmulas neurológicas tradicionais năo são tão especificas como anteriormente se pensava. Atualmente todas as sindromes que eram consideradas típicas out mesmo diagnósticas de enfarte têm sido encontradas em situações hemorrágicas, com exceção da síndrome de Wallenberg e, mesmo nesta, já foi descrito um caso em que se imputou hemorragia como causa. Estas realidades deverão fazer ponderar aqueles que anteriormente se propunham estabelecer decisōes terapêtuticas com agentes tais como anticoagulantes, fundamentados apenas em bases clinicas.

Demonstrar a causa de enfarte agudo está se tornando fato cada vez mais dificultado, em vez de facilitado, com a evoluçăo da tecnologia. A maioria das lesões primárias nos AVC ateroscleróticos são extracranianas 14,15,26, enquanto a maioria das lesões intracranianas săo de etiologia embólica 11,27,32,41. Estas observações fazem com que o diagnóstico clínico de embolismo seia hipótese a considerar em face de um AVC isquêmico associado a oclusão arterial única. Nos tempos mais recentes, com o recurso frequente de estudos angiográficos, tem sido difícil encontrar lesões ateromatosas das artérias de grande calibre $\mathrm{e}$, assim, as oclusões dos ramos arteriais intracranianos são geralmente explicadas como embólicas. O diagnóstico de AVC isquêmico de etiologia embólica é muitas vezes feito em presença de estudo angiográfico normal, pois a oclusão inicial frequentemente desaparece entre duas angiografias executadas com alguns dias de intervalo 11. Um grande grupo é atualmente reconhecido como senđo de enfarte de causa não determinada 19,51. Não obstante a utilização generalizada da TAC e angiografia, os clínicos têm-se visto desapontados nas suas expectativas de poderem estabelecer o mecanismo subjacente a um diagnóstico definitivo de AVC, pela simples aplicação de exames laboratoriais sensíveis 27.

Entre as variadas fontes emboligenas encontram-se as doencas cardiacas de vários tipos 13,38: fibrilação auricular 25, doença do nó sinusal, enfarte do miocárdio recente (especialmente ântero-septal), marântico 50 ou endocardite bacteriana subaguda, tumores cardíacos e válvulas prostéticas. A procura de doença cardiaca oculta é executada mediante monitorização prolongada, hemoculturas, ecocardiografia e, mesmo, cateterismo cardíaco.

$\mathrm{Na}$ falta de evidência de fonte emboligena óbvia, têm sido descritas fontes embolígenas nas paredes do arco aórtico e nos vasos extracranianos. Têm sido igualmente descritos êmbolos em alguns casos de ulceraçōes de instalaçăo aguda e, mesmo mais tardiamente, em casos de oclusão carotidea 5. AVC em paciente com doença carotidea foi durante vários anos aceito como de etiologia mais provavelmente embólica, do que por falência de perfusão 46. Uma vez estabelecidas estas correlações, levanta-se a questão de saber qual a severidade possivel de um AVC em relação com o grau de lesão carotidea. Os AVC embólicos atribuidos a placas de cálcio têm sido raramente descritos, raramente também sendo tais placas causa de acidentes extensos 31,34,45 mas, a conviç̧ão de que existiria uma associação com AVC embólicos, levou a que lesões cada vez menores tivessem sido encontradas na cirurgia 31 . Desde que estas fontes foram definidas, o significado do termo "embolismo" teve de ser ampliado de modo a incluir fontes não-cardiogênicas. A demonstração de que o material embólico podia variar consideravelmente em tamanho constituiu um ponto a mais de dificuldade. 
Conduto, em muitos AVC, nos quais aspectos angiográficos ou da TAC apontam para enfartes superficiais extremamente bem delimitados, nenhuma fonte embolígena é aparente 19. Mais frustrante ainda, tem sido a alta incidência de enfartes de causa indeterminada 19,51. Esta alta incidência não pode ser atribuída à utilização de esforços mal dirigidos: com efeito, estes diagnósticos têm sido feitos em maior número nos centros em que os recursos TAC e angiografia são empregados de modo mais generalizado. Este aspecto mostrou-se particularmente nitido durante a fase piloto do projeto "Stroke Data Bank", quando o centro participante com maior utilizaçāo de TAC e angiografia teve a maior incidência de AVC de causa indeterminada $19,32,41,51$.

Não restam dúvidas de que alguns fatores contribuem para dificultar o diagnóstico etiológico do enfarte. As explicações mais comuns são a năo execução dos exames adequados ou a não execução dos testes apropriados en tempo oportuno ou, ainda, achados normais ou sujeitos a ambiguidade de interpretação. As principais causas que levam a interrupção do estudo de um doente são: idade avançada, doença grave e de mau prognóstico concomitante, recusa do doente ou do médico na execuçăo de determinados exames e a crença num determinado diagnóstico baseado apenas em aspectos clínicos. A confiança que existia anteriormente no estabelecimento do diagnóstico de um determinado tipo de AVC, apenas fundamentado nos aspectos clínicos, tem sido gravemente erodida nos últimos anos. Nas síndromes lacunares em particular, têm sido atribuidas várias causas 40.

A segunda causa frequente para a falha na determinação da causa do enfarte é a não execução, em tempo próprio, dos exames adequados. Os problemas mais frequentes resultam da execução demasiado precoce da TAC e demasiado tardia da angiografia. As angiografias para detecção de embolias executadas mais de 48 horas depois do ictus são positivas para evidenciar a oclusão responsável em apenas cerca de $15 \%$ dos casos 11,41, mesmo nos casos em que a angiografia inicial fora positiva. As TAC executadas apenas uma vez, nas primeiras horas após a instalação do AVC isquêmico, são normais em quase $50 \%$ dos casos 51 .

Resultados de testes sem achados concludentes constituem um número preocupante. Cerca de $40 \%$ dos casos de AVC isquêmico de causa indeterminada năn evidenciam anomalias, não obstante terem sido executados os estudos apropriados na época devida 19 . Os estudos angiográficos contêm muitos aspectos que continuam a determinar problemas de interpretação, incluindo aqueles em que à primeira vista parecem nāo deixar dúvidas, tais como oclusōes e estenoses 27 . Se bem que as oclusōes de ramo, na ausência de outra doença oclusiva, tenham sido aceitas como sugestivas de embolismo, o certo é que oclusões de ramo, isoladas, podem ocorrer em arterites. Nos casos de oclusão do tronco da artéria cerebral média, a doença ateromatosa é atualmente reconhecida como causa, especialmente em pacientes de raça negra. A dissecção arterial intracraniana, embora sendo ainda ııma raridade, é contudo uma possibilidade. As estenoses, que pareciam ser um aspecto bastante sugestivo de aterosclerose dos vasos extracranianos, também têm sido consideradas, pois tem sido documentado que a recanalização de êmbolos mimetiza aspectos da aterosclerose 26,27, e estenoses também têm sido verificadas em dissecçóes e arterites 43 . O diagnóstico de embolismo só pode ser feito com segurança quando se documenta angiograficamente a oclusăo e, num estudo subsequente realizado alguns dias depois, que a oclusão inicial tenha desaparecido. Contudo, este estudo invasivo poucas vezes é realizado, por se iulgar demasiado agressivo. Quando muito, a trombose poderá representar apenas $2 \%$ dos acidentes isquêmicos do território da artéria cerebral média 26 , fazendo com que o diagnóstico de embolismo, de etiologia conhecida ou năo, seja uma inferência lógica. As estenoses multissegmentares são um aspecto de arterite, quer seja o resultado de doença arterial primária quer de doença secundária a infiltração meningea, mas também é vista na fase de remissão do chamado vasospasmo devido a embolia, hemorragia subaracnóidea ou trauma.

De todos os mecanismos năo provados, a embolização a partir de uma fonte ocıllta, provavelmente encabeça a lista. O clínico poderá ver baldados seus esforços para o diagnóstico, quer por ser a fonte da partícula suficientemente larga para causar o AVC e demasiado pequena para ser detectada pelo meio diagnóstico utilizado, não produzir embolização clinicamente evidente noutro local, ou de fato desaparecer antes de ser detectada. Fontes pouco frequentes de partículas aue seiam suficientemente grandes para causar bloqueios de ramos ou do tronco da artéria 
cerebral média incluem: embolias "paroxísticas" de uma veia do membro inferior. prolapso da válvula mitral, mixoma auricular, embolias marânticas, mucina e gorduras enulsionadas de metástases de neoplasias da mama, endocardite devida a Candida, fragmentos de parede arterial após ressuscitaçăo, dissecção espontânea da artéria carótida interna em caso de hiperplasia fibromuscular, dissecção traumática da artéria carótida interna, máterial cálcico da artéria carótida interna ipsilateral, oclusão da artéria carótida interna de várias causas, aneurisma fusiforme gigante da artéria cerebral média, complexos fibrino-plaquetários a partir de placas não obstrutivas da artéria carótida interna, bala de pistola e oclusão da artéria carótida interna de várias causas 5,38. Em alguns casos a sindrome clínica é de tăo curta duração que já foi feito o diagnóstico de AIT 21,39,45. Diagnósticos tardios da causa original são pouco frequentes.

Finalmente, etiologias pouco frequentes poderão constituir problemas diagnósticos entre as quais se encontram a enxaqueca, arterite intracraniana e a entidade mal conhecida que constitui a doença de Binswanger 5,18.

\section{DIAGNÓSTICO LABORATORIAL}

Radiografia simples de crânio e do pescoço - não têm geralmente interesse no diagnóstico do AVC águdo. As calcificações vasculares têm pouca relevância para o grau de severidade do AVC e, geralmente, nem mesmo na identificaçāo da etiologia do AVC, exceto nos casos pouco frequentes de MAV. Efeitos de massa de alguns AVC são evidentes quando a glâridula pineal calcificada se encontra desviada da linha média.

Tomografia Computadorizada - tornou-se popular a partir de $1973 \mathbf{5 , 1 0}$. Seu impacto dramático no diagnóstico dos AVC é tāo bem conhecido que os comentários necessitam apenas de ser dirigidos para certos problemas diagnósticos não resolvidos. Um diagnóstico preciso pode ser feito nos hematomas agudos, com a sua elevada densidade aparecendo na primeira semana, mas com pouco rigor depois disso. A TAC executada nos primeiros dićs pode ser normal nos enfartes não hemorrágicos, mostrando baixa densidade devido ao edema. Enfartes que se tornam rapidamente edematosos, como nos casos de grandes oclusões embólicas, podem ser positivos dentro de 24 horas, enquánto que alguns, devido a insuficiência distal sem débito colateral, podem manter-se persistentemente negativos, aparecendo como atrofia focal na fase crônica 51.

Não existe qualquer critério seguro para separar os hematomas lobares dos enfartes hemorrágicos 29 . Têm sido documentadas patologicamente hemorragias confluentes nítidas e não apenas petéquias esparsas, em casos em que a TAC apresenta aspectos isodensos ou mesmo hipodensos. Se estes achados são representativos, eles sugerem que enfartos hemorrágicos severos têm de estar presentes antes dos aspectos hiperdensos característicos aparecerem na TAC.

A TAC revela também muitos enfartes profundos 40 . Se bem que muitas vezes classificados como lacunas, algumas destas hipodensidades representam 0 aspecto tardio de hematomas parenquimatosos, outras serão o aspecto agudo de embolização que afetou o tronco da artéria cerebral média, outras serão o sinal de estenose ateromatosa da própria artéria cerebral média. Não existem ainda meios exatos para permitir a distinção entre essas possibilidades. Tem sido tentador, para alguns autores, atribuir várias perturbaçōes de linguagem a esses enfartes profundos visualizados na TAC. Recomenda-se precaução neste ponto, uma vez que a maioria deles tem sido documentada apenas por TAC e só alguns foram estudados patologicamente. Em vez de etiologia lacunar, muitos dos grandes enfartes profundos têm um componente cerebral superficial que reflete sua origem embólica. $O$ componente superficial não é sempre facilmente visualizado na TAC, podendo ser pequeno e estar oculto no padrão giriforme da convexidade. Conclusões fisiopatológicas a respeito destas lesões profundas podem eventualmente ser revistas à luz de melhores provas.

Ressonância Magnética Nuclear - Provou já sua superioridade em relação à TAC para todos os tipos de AVC 23,55. Para diagnosticar e datar as hemorragias, são necessárias tanto as sequências de pulso $\mathrm{T} 2$ como $\mathrm{T} 1$, mas para o enfarto é preferivel um T2 longo 28,36 . O efeito paramagnético único da meta-hemoglobina $\mathrm{e}$ da hemossiderina permitem até datar os hematomas e fazer a separação entre hematomas e enfartes hemorrágicos 7,17. A ausência de sinal do osso torna a ressonância 
magnética a técnica de escolha para os enfartes do tronco cerebral. Esta ausência de sirial é também característica do sangue circulante, permitindo à ressonância magnética documentar MAV e vasos recanalizados 17.

Débito Sangtineo Regional - Baseia-se no uso de xenônio radioativo, marcado, administrado geralmente por inalação mas podendo também em alguns casos ser addministrado por injeção intracarotidea 30.33 . O registro da concentração de xenônio radioativo, proporcional ao débito sanguíneo regional, é captado por meio de detectures colocados sobre o escalpe. Este estudo é um guia sensivel do grau de perfusāo na superfície cerebral, mas é menos sensivel na deteç̧ão das regiões profundas do cérebro. Este teste permite avaliaçāo da vasorreatividade. Provocando hiperventilação com ar ambiente na mistura, produz-se normalmente vasoconstrição; assim a ausência de resposta nestas condiçōes, numa determinada regiāo cerebral, serve de sinal de perda de vasorreatividade como acontece nos casos de enfarte na fase aguda. Com efeito, a hiperventilação com mistura de ar contendo pequena guantidade de dióxido de carbono causa normalmente vasodilatação; assim, a ausência de resposta indica que o leito vascular nessa região já se encontra dilatado 8.12 . Este sinal indica aumerito de rede vascular colateral, o que frequentemente ocorre em situações de oclusāo ou estenose hemodinamicamente significativas das carótidas extracranianas.

Angiografia - Como meio de evidenciar as estruturas cerebrais, já não é mais utilizada no diagnóstico de efeito de massa e nunca foi útil no diagnóstico de lesão parênquimatosa. Mantém-se, contudo, como método de escolha quando o diagnóstico depende da demonstração de oclusão, recanalização, ulceração ou dissecção dos grandes vasos a estenose das pequenas artérias. Mantém-se ainda como o método de eleiçāo para o diagnóstico de aneurismas e MAV. Porém a angiografia, tal como a TAC e a RMN, depende de tecnologia dispendiosa e apresenta risco na sua execução, embora este possa ser pequeno.

Ultrassonografia por Efeito Doppler - Ultrapassou já sua fase primitiva e pode agora ser utilizada para insonar e representar graficamente vários vasos que anteriormente necessitavam de estudo angiográfico 56 . Um sinal de alta frequência em onda contínua é dirigido através dos tecidos do pescoço e cabeça e recupera-se o sinal refletido de modo a poder-se determinar a direção do fluxo e a velocidade das particulas em movimento na trajetória do feixe ultrassônico. Os instrumentos de Doppler
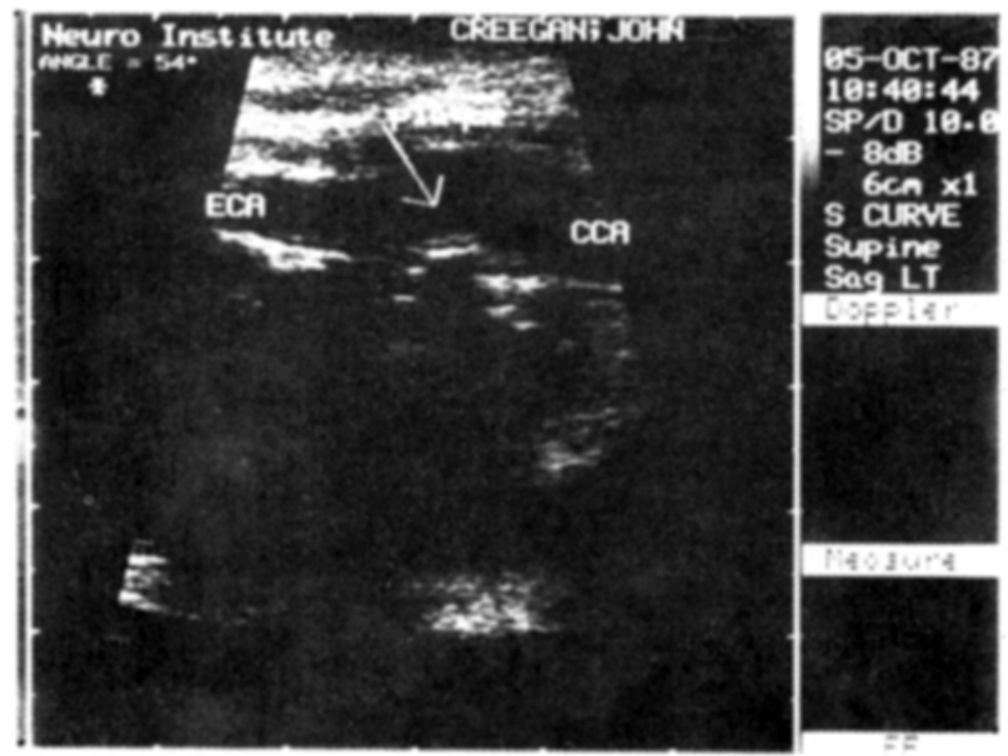

Fig. 1 - Estenose hemodinamicamente não significativa na bifurcaç̃o carotidea, causada por uma placa, visivel na figura como uma imagem ecolucente. Note-se a zona de "sombra" ecogenea subjacente. 


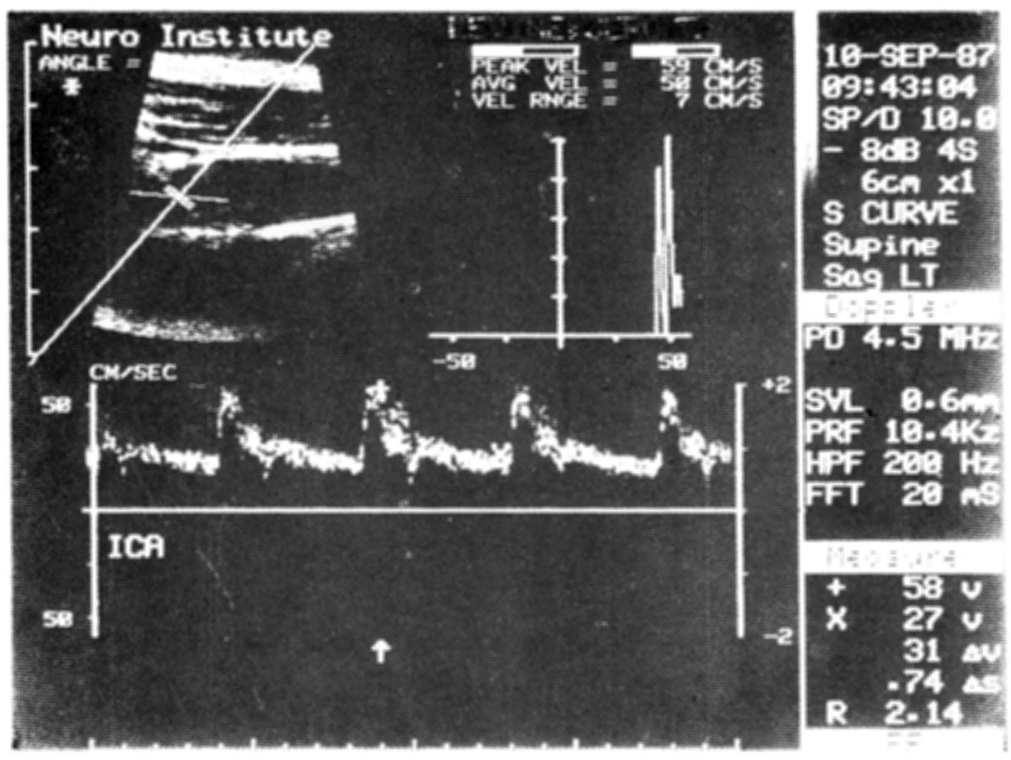

Fig. 2 - Módulo duplo (mixed mode) de uma artéria carótida interna. $A$ imagem em módulo-M está representada no canto superior esquerdo, enquanto na parte inferior da figura se representa a onda Doppler correspondente ao ponto indicado pelo cursor em módulo-M. No canto superior direito representa-se a análise espectral no ponto da onda indicado pela seta.
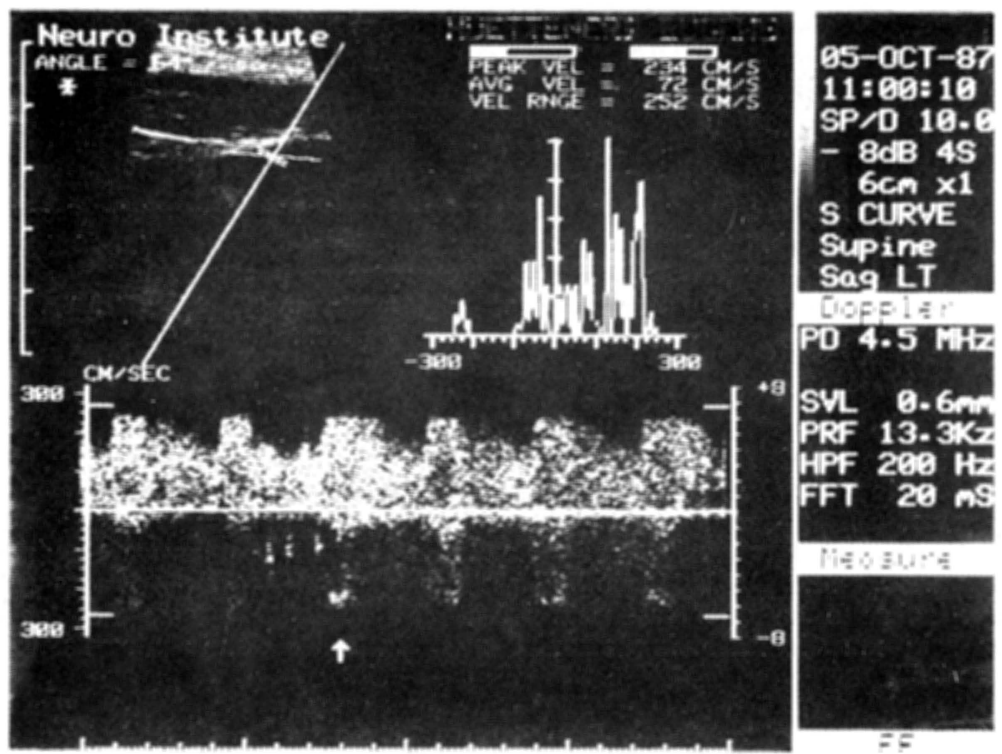

Fig. 3 - Estenose severa (80\% e 99\%) determinada por análise do efe to Doppler. Note-se o alargamento da base das ondas $e$ o pico sistólico elevado que ultrapassa os limites do gráfico, aparecendo na parte respectiva inferior. Na analise espectral verifica-se grande alargamento das bandas, significando turbulência. A placa é ecotransparente, não sendo visualizada em Modulo-M. 

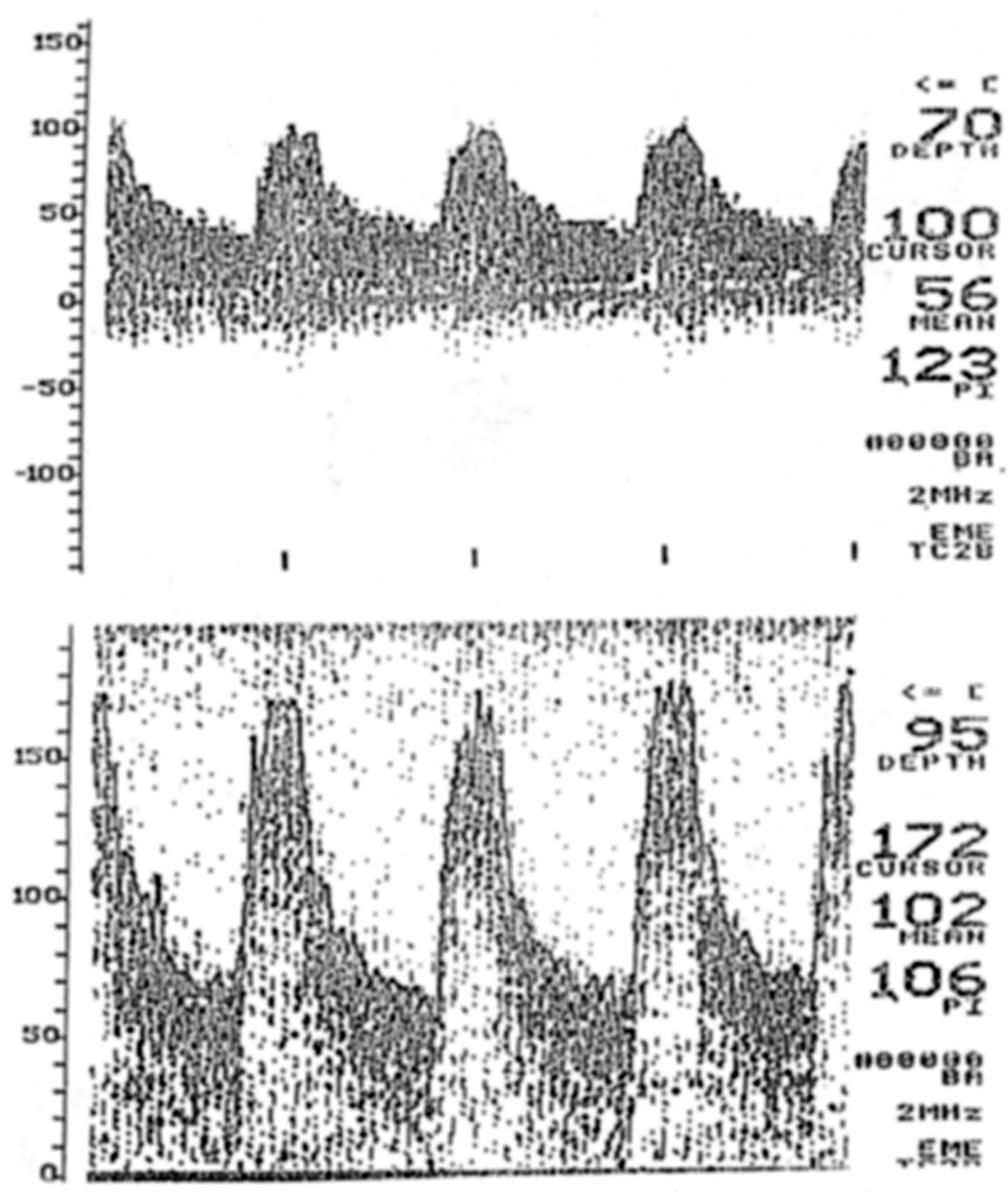

Fig. 4 - Sinais indicativos de aumento de velocidade cinculatória (localizada) na artéria basilar a uma profundidade de $95 \mathrm{~mm}$ (em baixo), comparativamente as aspectos encontrados a uma profundidade de $75 \mathrm{~mm}$ (em cima). 0 estudo angiografico da artéria basilar (Fig. 5) evidenciou estenose, particularmente no segmento distal.

de onda contínua (DOC) são de preço acessivel e suficientemente sensiveis para detectarem desvios significativos da onda refletida, através de partes moles tais como as do pescoço. Relativamente pouca experiência é necessária para identificar um sinal arterial de alta frequência produzido por uma estenose severa de uma carótiđa extracraniana. Contudo, a equação do efeito Doppler depende do cosseno do feixe ultrassônico sobre o sangue circulante intra-arterial, fazendo com que o ângulo do transdutor seja um elemento fundamental no estudo do débito através das artérias estenosadas 49,58 .

Para ajudar na obtenção do ângulo correto, os modernos aparelhos de Doppler Duplex possuem dois cristais, um sobre o outro, num transdutor com uma única cabeça: um cristal detecta os sinais Doppler para análise espectral, enquanto o outro permite registrar imagens ecográficas em "Módulo-B". A alta capacidade de resolução do "Módulo-B" utiliza um transdutor pulsátil de $7,5 \mathrm{MHz}$ ou $10 \mathrm{MHz}$ e permite insonar a face ântero-lateral do pescoço a diferentes níveis, recolhendo sinais das diversas estruturas vasculares $\mathbf{5 6 , 5 8}$. O fato de a ecolucência das placas ateroscleróticas terem grande variabilidade, indo desde as grandes densidades cálcicas até a 


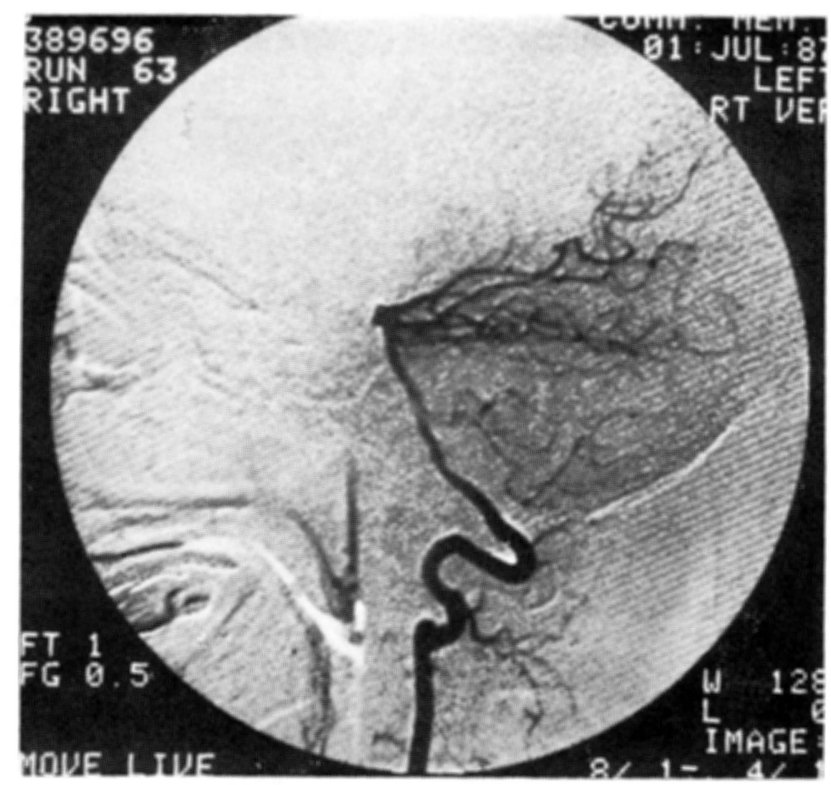

Fig. 5 - Estudo da circulaç̃̃o posterior, evidenciando segmentos este. nosados.

transparência ecográfica, nos casos de placas recentes de constituição fibrino-plaquetária, torna razoável concluir que considerável numero de lesões pode ser subestimado ou passar mesmo completamente despercebido quándo se utiliza o "Módulo-M" isoladamente.

Com a utilização simultânea da análise espectral do efeito Doppler, é possivel determinar a velocidade circulatória e a forma da onda sisto-diastólica. Esta análise adicional é de grande interesse, nāo apenas nos casos de placas transparentes aos ultrassons, mas também nas situações de placas heterogêneas de modo a poder-se estimar seu significado hemodinâmico real.

As melhorias verificadas no desenho dos cristais têm reduzido cada vez mais o támanho dos transdutores mas, mantêm-se contudo demasiado grandes para permitirem uma boa insonação nos segmentos superiores das carótidas, particularmente a partir do ângulo da mandíbula. O objetivo do Duplex Scan é ampliado pela interpretação dos sinais Doppler que permitem tirar conclusões para além dos linites anatômicos de insonação. Assim, diminuição do fluxo no segmento proximal da artéria carótida primitiva significa provável estenose na origem da artéria subclávia ou, quando se verificam sinais de aumento de resistência, isto será sugestivo de lesăo estenosante distal, como por exemplo estenose do sifão carotídeo.

Os cristais utilizados modernamente para detecção do efeito Doppler têm a capacidade de permitir ajustar a frequência em relação à emissão dos pulsos ultrassônicos, de modo a possibilitar a análise dos sinais de fluxo obtidos a partir de profundidades pré-estabelecidas, eliminando assim a obtenção de sinais resultantes da mistura do efeito ultrassônico sobre regiōes onde artérias e veias se sobrepōem e que perturbariam a interpretação dos dados. Os aparelhos mais sofisticados possuem duas possibilidades de produzir frequências ajustadas ao pulso ultrassônico permitindo a adequação do "volume" ou "janela", para insonar a coluna móvel de sangue numa artéria, a volumes tão pequenos como $0,6 \mathrm{~mm}$, correspondente às dimensões das estenoses mais cerradas. Com a utilização de tais "janelas" ajustáveis, os aspectos da angulação perdem importância, uma vez que os sinais de elevada turbulência encontrados apenas nas "janelas" mais estreitas devem representar estenoses severas, não obstante o ângulo de insonação. 

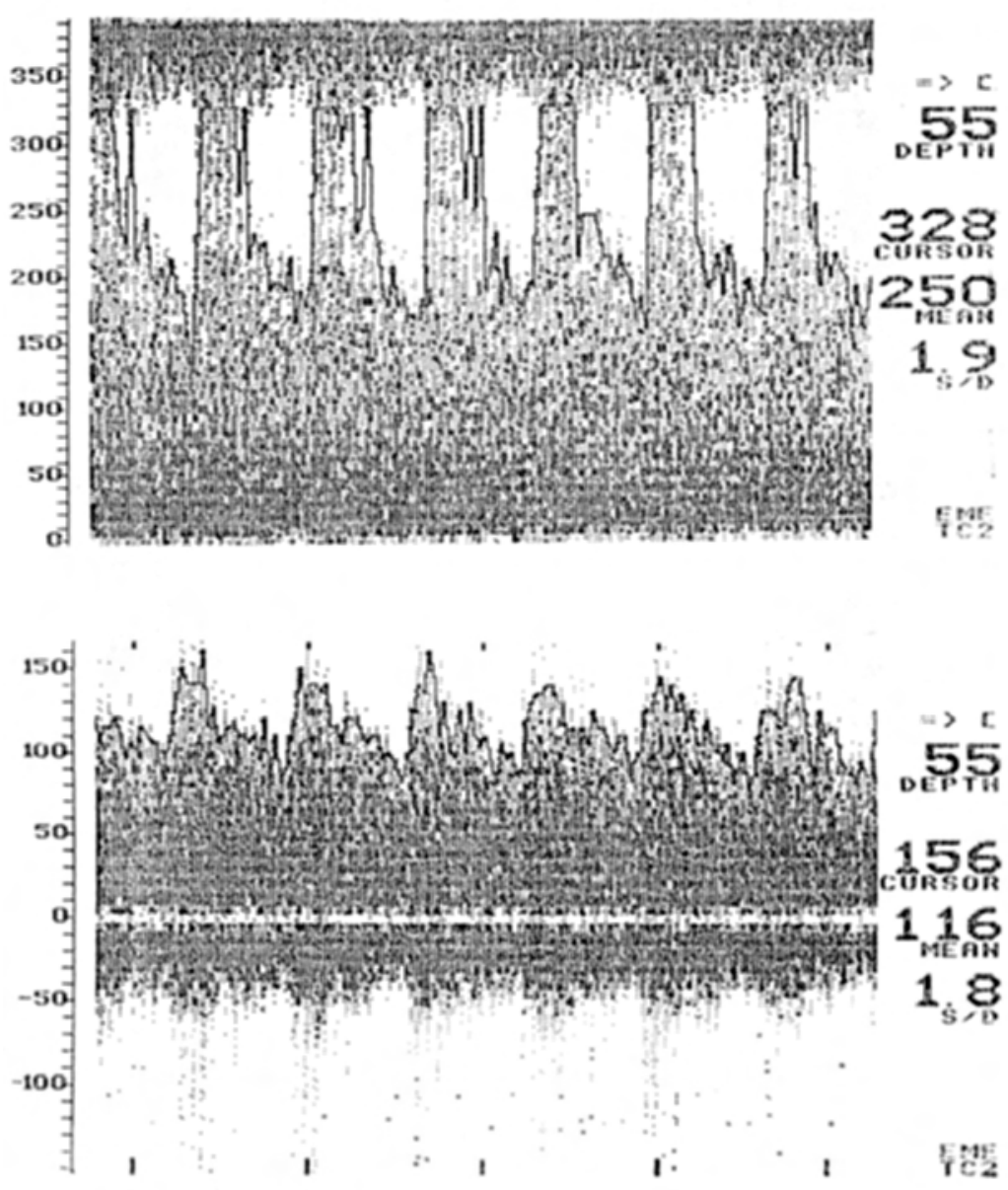

Fig. 6 - Estudo com DTC das arterias cerebrais médias a uma profundidade de $55 \mathrm{~mm}$, num doente apresentando vasospasmo pos-hemorragia subaracnoidea. Verifica-se aumento bilateral das velocidades sistolicas: 116 a direita e 328 à esquerda (normal <94); os valores mais elevados correspondiam ao lado da rotura aneurismática.

A possibilidade de obter sinais do padrão de fluxo circulatório de parede através do lume do vaso fez desta técnica instrumento sensível para a detecção, medição e monitorização do grau de estenose. Uma vez que é sensível à área de secção transversal e não à anatomia da parede, permite que sua utilização antes do estudo angiográfico possa muitas vezes dirigir a atenção do radiologista na procura de estenoses que, devido ao posicionamento anatômico do pescoço, combinado à presença de estenoses assimétricas não anulares, poderiam eventualmente passar desapercebidas ou não serem devidamente valorizadas num estudo angiográfico de tipo convencional. Esta técnica permite também o estudo do território vertebral, tal como o do carotídeo.

O Doppler Transcraniano foi introduzido em 1982 por R. Aaslid 1,2 e consiste fundamentalmente num dispositivo de ultrassons provido de efeito Doppler e ligado a transdutor de tipo pulsátil de $2 \mathrm{MHz}$. Esta sonda tem capacidade de penetração tissular suficiente para permitir a insonação dos vasos do polígono de Willis, artérias vertebrais e basilar através da calota craniana. Estes aparelhos têm também pulso "gated" mas não possuem ainda Duplex; assim sendo, não é possível obter imagens do vaso. Os sinais assim obtidos documentam a direção e a velocidade do débito 

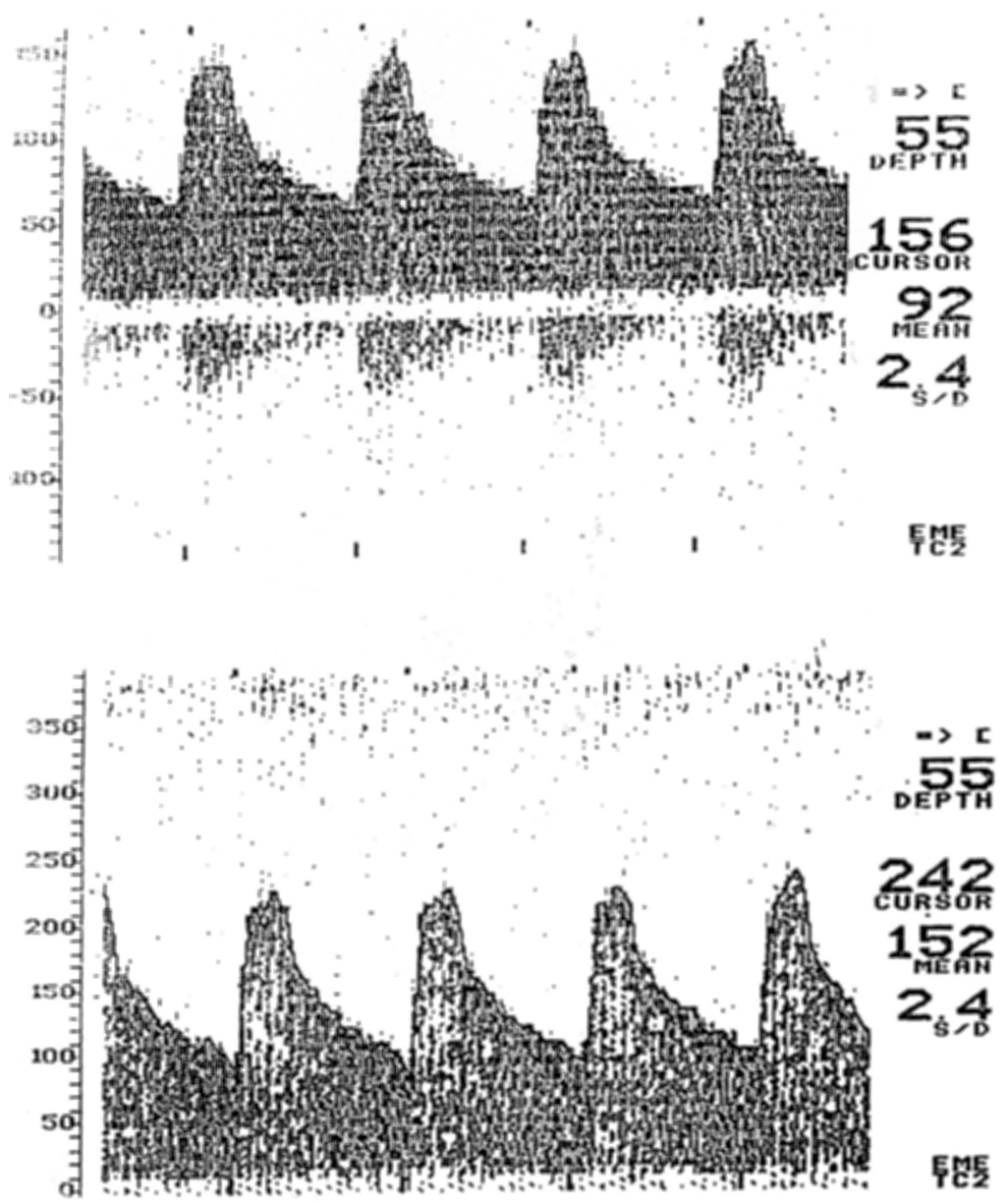

Fig. 7 - Estudo com DTC evidenciando aceleração localizada no segmento da artéria cerebral média esquerda a uma profundidade de $55 \mathrm{~mm}$ (imagem inferior, esquerda; imagem superior, direita). Este aspecto sugestivo de estenose foi confirmado por angiografia (Fig. 8).

sanguíneo insonado pelo foco ultrassônico e a análise espectral do sinal permite estimar o grau de estenose tal como o faz o Doppler Duplex extracraniano. Colocando a sonda sobre zonas de menor densidade óssea existentes na calota craniana, é possivel obter o efeito Doppler do feixe ultrassônico depois de este ser refletido pela coluna de sangue circulante intravascular do poligono de Willis e dos seus ramos principais 3,8 . Os sinais assim obtidos são registrados, permitindo tirar conclusões acerca das características da velocidade circulatória e, assim, sobre o grau de permeabilidade dos diversos vasos em estudo e a diferentes profundidades.

Existem três vias principais de acesso à circulação intracraniana 1 . A primeira é a via fronto-zigomática, a qual se obtém colocando a sonda na região têmporozigomática, ligeiramente acima da arcada zigomática. Ai se localizam "três janelas" dispostas uma a seguir das outras, permitindo obter sinais da artéria cerebral média, segmento pré-comunicante da artéria cerebral anterior e artéria cerebral posterior. A segunda via é a oftálmica. Esta via pode ser utilizada colocando a sonda sobre a pálpebra superior cerrada e dirigindo o foco medianamente e no sentido ânteroposterior; é assím possível obter sinais da artéria oftálmica e, mais profundamente, do sifão carotídeo. Finalmente, a via occipital é acessível colocando a sonda sobre 


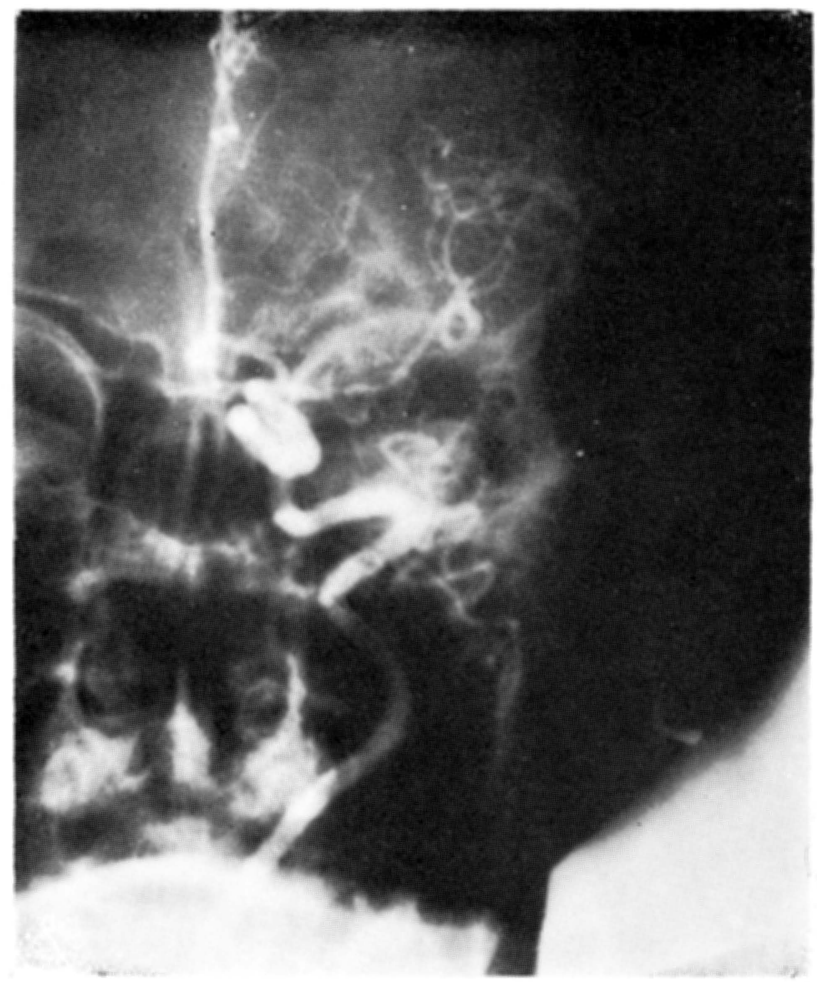

Fig. 8 - Estudo angiográfico da artéria cerebral média esquerda evidenciando segmentos estenosados.

a região cervical posterior, dirigindo o feixe ultrassônico no sentido póstero-anterior, na região suboccipital, por cima da primeira vértebra. Por esta via é possível recolher sinais da artéria basilar em toda a sua extensão; é também possível obter sinais das artérias vertebrais e cerebelosa póstero-inferior.

Quando existe estenose severa, como nos casos de ateroma, vasospasmo ou recanalização de êmbolo, obtêm-se sinais localizados de velocidades aceleradas sugestivos de turbulência 2,4,8. Nos casos em que uma das principais artérias extracranianas, tal como as carótidas, fica severamente estenosada ou ocluída, a forma das ondas na artéria cerebral anterior ipsilateral pode ter o sentido invertido, indicando circulação colateral do lado oposto e a forma das ondas da artéria cerebral média pode encontrar-se consideravelmente aplanada, devido ao efeito da grande distância que o sangue tem de percorrer através da circulação colateral para atingir esse local. Pode realizar-se uma manobra de compressão contralateral para testar o efeito que produz a estenose unilateral extracraniana para compensar a baixa de débito nesse lado ou se existe déficit de circulação colateral.

E necessária atenção especial, para se saber qual a artéria que está sendo insonada, pois as artérias cerebrais médias e posteriores são muitas vezes confundidas. Esta técnica depende em grande parte da habilidade do executante e requer quantidade razoável de paciência para detectar o sinal e, depois, encontrar o melhor ângulo de insonação para cada grau de profundidade. Variações anatômicas inesperadas perturbam as caracteristicas do sinal.

Não obstante essas pequenas dificuldades, os estudos ultrassonográticos por efeito Doppler têm ganhado adeptos devido às suas caracteristicas: pequenas dimensões do aparelho, que é facilmente transportável e pode ser levado para sala de emergência, sala de operações, sala de cuidados intensivos, cabeceira do doente ou, mesmo, ao domicílio. Os sinais obtidos são fácil e adequadamente analisados por um microcomputador e permitem diagnostico de vasospasmo, circulação colateral distal a oclusões, 


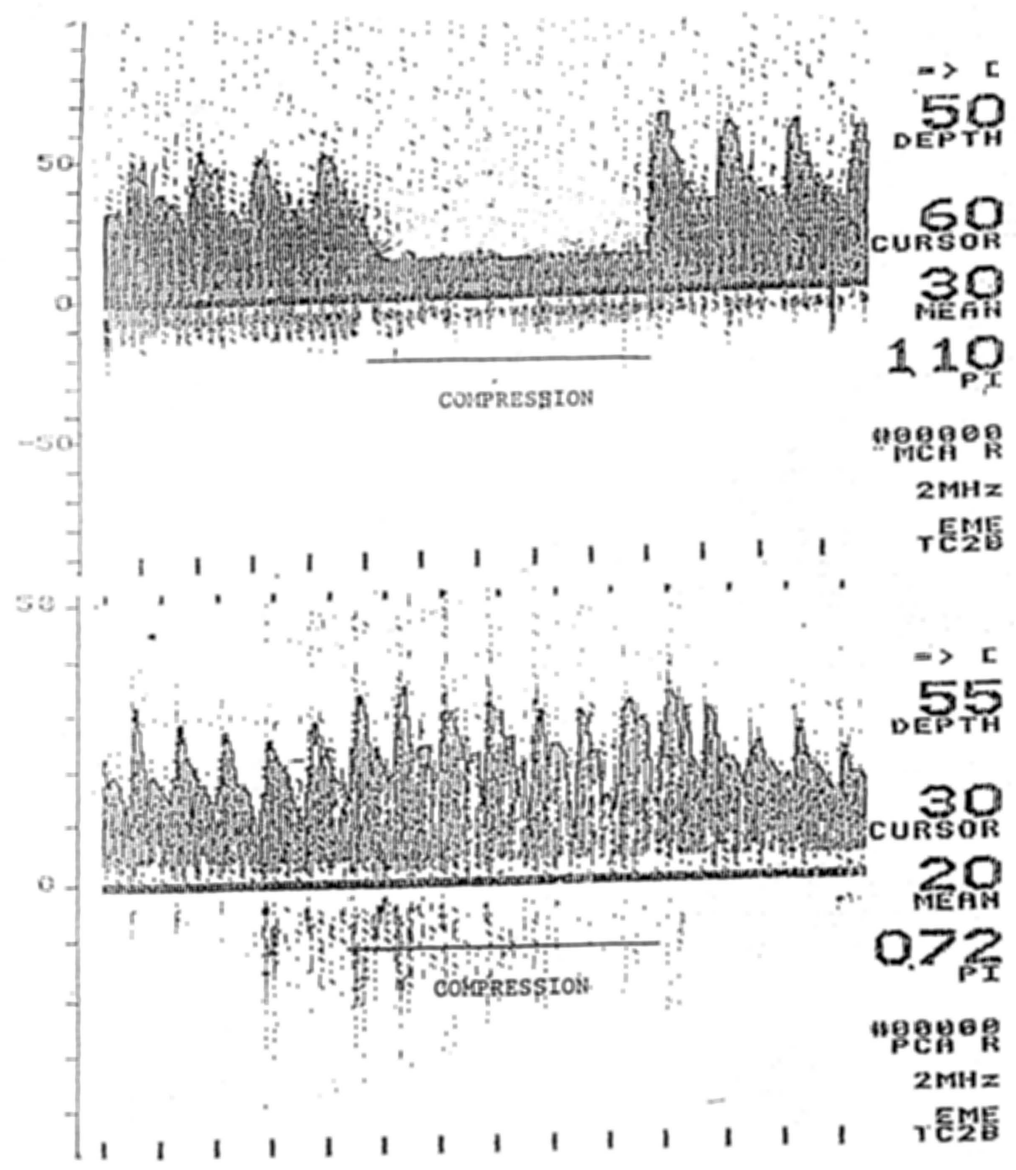

Fig. 9 - Manobras de compressão: comprimindo a artéria carótida primitiva é possivel registrar alteraç̃es da hemodinamica cerebral, mostrando a permeabilidade do poligono de Willis $e$ sua capacidade de assegurar o débito sanguíneo necessário no caso de oclusão de uma carótida estenosada. Estes aspectos podem ser importantes na decisão terapêutica.

recanalização de artéria ocluida por êmbolo, bem como presença de estenose basilar ou cerebral importantes. Este teste pode ser repetido com inocuidade, de modo a seguir-se o curso de uma doença oclusiva 8 , sendo o custo do equipamento relativamente baixo comparativamente às formas tradicionais de obter imagens do parênquima cerebral ou da circulação intracraniana 20. Obtêm-se também informações sobre o débito e sobre a rede colateral, a qual não é facilmente acessivel por outros meios 8 . Seu uso cada vez mais difundido permitirá melhor documentação das variações dos fenômenos circulatórios nos AVC agudos e a sua resposta à terapêutica 54 .

\section{PROGRESSÃO DO AVC}

Tem sido dispensada bastante atenção ao tema do AVC em progressão, pois persiste a esperança de que aquilo que pode se tornar num déficit devastador, poderá ser detectado e combatido nas fases precoces de evolução. Tem sido também muito difícil documentar um AVC em evolução bem como o seu perfil.

A evidência da existência da chamada "penumbra isquêmica" tem sido procurada desde há vários anos, mas tem se mostrado geralmente vã $e$, quando ocasionalmente encontrada, é apenas uma zona desapontadoramente pequena e estreita como melhor tem sido detectado pelos estudos radiográficos executados nos últimos anos 6,48. Os estudos neuropatológicos têm regularmente indicado um limite bastante nítido entre $o$ tecido saudável e o isquêmico, ao mesmo tempo que estudos quantitativos do 
enfarte têm sido feitos numa grande variedade de tipos de AVC. Permanece por esclarecer a questão de saber até que ponto as técnicas futuras, com imagem de alta resolução, poderão atingir aquilo que as técnicas atuais não conseguem objetivar. Por enquanto, devemo-nos sentir frustrados quando se levanta a questão de saber o que acontece quando o déficit aumenta.

O perfil da degradação da situação neurológica é nitidamente não-uniforme nos vários subtipos de AVC: menos frequentemente naqueles que parecem ser de mecanismo embólico e mais frequentemente naqueles que parecem ser de mecanismo trombótico, quer afetem um vaso de grande ou pequeno calibre. $O$ fato de existir elevada freqüência de casos que parecem ser de natureza embólica levanta a velha questão de saber se um enfarte pode ser devido a falência de perfusão. Mas, ao tentar-se esclarecer o assunto da falência de perfusão, através do estudo dos aspectos clínicos da "progressão" ou "agravamento" do AVC isquêmico, chegou-se à demonstração de dois tipos de agravamento. No primeiro, a fórmula do déficit modifica-se de modo a atingir zonas anteriormente poupadas; este é o tipo de evolução que deve se relacionar com a progressão topográfica da lesão e provavelmente representa falência de perfusão 38 . O segundo representa intensificação do déficit inicial, sem alteração da fórmula, um efeito que sugere conversão da isquemia em enfarto, o que representa um efeito diferente da falência de perfusão. Evidência para consubstanciar estes dois tipos de falência tem sido tão difícil de obter como para demonstrar a penumbra isquemica $22,23,48$.

Poucos estudos têm sido feitos especificamente dirigidos na tentativa de identificar os diferentes mecanismos que podem contribuir para o agravamento da situação e ainda menos estudos clínicos têm sido organizados no sentido de esclarecer uma ou outra das fórmulas clínicas de agravamento. Pelo contrário, a maioria dos ensaios clínicos tem sido dirigida para o objetivo de abarcar tantos doentes quantos os que estiverem de acordo em particpar no estudo, um objetivo cujo valor nem sempre é alcançado. Pelos nossos cálculos, será necessário grande número de doentes para se poder demonstrar o efeito de uma determinada terapêtutica. Devido à observação desencorajante de que poucos doentes numa instituição preencherão as condições para entrar no estudo, tal objetivo deverá mostrar-se impraticável.

Esses obstáculos deixam os clínicos indecisos sobre o que fazer em face da perspectiva de deterioração num AVC agudo 35 . Infelizmente, parece existirem poucas razões para esperar que, corrigindo parầmetros metabólicos anormais, poderá melhorar-se a situação, uma vez que essas alterações são raras e, quando presentes, parecem não ter relação com o agravamento da situação neurológica 42 . Isto não significa que os doentes devam permanecer sem tratamento para correção dessas situaçóes, pelo contrário, o que não se deverá é ter grandes esperanças de que, com a correção dessa situação, se consiga reverter o déficit focal agudo. Do mesmo modo e não obstante a atenção dada à hiperglicemia, sua importância no agravamento do enfarte parece ser apenas qualitativa, pois níveis de glicemia no limite inferior dos parâmetros do doente ambulatório são mais que suficientes para agravar um enfarte e, apenas uma extrema hiperglicemia, parece contribuir para o agravamento do tamanho do enfarte e agravamento clínico. O ensinamento parece ser o de manter um nivel baixo de glicemia (inferior $100 \mathrm{mg} \%$ ) em pacientes que vão ser submetidos a pequenos procedimentos tais como angiografia, mas não existem boas razóes para reduzir o nivel de glicemia, exceto nos casos em que se encontrem nos níveis de diabetes. Convém debruçarmo-nos um pouco para considerar se a tradição consagrada pelo tempo, de ministrar glicose a $50 \%$, nos serviços de urgência, terá algum interesse $\mathbf{4 2}$.

A redução do hematócrito para os niveis ideais continua a ser um objetivo atraente; a evidência tem demonstrado que poucos doentes têm hematócritos suficientemente elevados de modo a imporem uma redução dramática, enquanto que o hematócrito moderadamente aumentado parece ter um efeito irrelevante no tamanho do enfarte e no seu agravamento.

$O$ agravamento em alguns tipos de AVC, especialmente pequenos enfartes profundos do tamanho de "lacunas", poderá ter um prognóstico notavelmente favorável 40. Muitos dos enfartes lacunares, que se agravam progressivamente durante alguns dias, apresentam recuperação quase completa, o que constitui um ponto a favor da antiga noção de que o edema peri-lesional nos enfartes é responsável pelo agravamento da situação e que o déficit volta à sua expressão inicial depois de o edema ter regredido. $O$ uso de heparina é ainda controverso. Um trabalho publicado apenas neste ano vem contribuir de algum modo para o esclarecimento da questão do benefício ou não 
da terapêutica com hepariria. No entanto, o tamănho da amostragem parece ser demasiado pequeno para permitir tirar conclusōes e, se for conduzido com maior número de doentes sem alteração das percentagens, o que julgamos terá de acontecer, mostrará que a heparina previne realmente o agravamento da situação. Existe abundante evidência de que a heparina pode ser utilizada com grande segurança e pode ter importância nâ prevenção das recorrências. Considerando contudo as dificuldades em distinguir agravamento de recorrência, a utilização da heparina parece justificada mesmo nos casos de recorrência apenas, ainda que não tenha interferência no agravamento. Em face da evidência da falência de perfusão, continuamos a recomendar a endarterectomia em doentes com estenoses acentuadas e evidência de tal situação usando, para documentar a perturbação da perfusão cerebral, técnicas como Doppler transcraniano ou 133-xenônio. outras.

Para a doença da basilar, poucas armas terapêtucas existem, racionais ou

\section{RECORRENCIA DO AVC}

O risco de recorrência não é assunto pacífico 52. A certa altura existiu a esperança de que o risco de recorrência fosse diminuto: as hemorragias parenquimatosas quase nunca se repetem, as tromboses das grandes e mesmo das pequenas artérias podem ser tomadas como exemplo de "AVC estabelecido" e apenas os AVC com fonte emboligena cardíaca pareciam sujeitos a maior risco de recorrência e mesmo esse risco, provavelmente exagerado, era comparável ao risco das complicações da terapètica com anticoagulantes e por esta razão a anticoagulação poderia ser adiada 47,53,57. Dados recentes destituem-nos destas regras tradicionais. A recorrência não parece afetar os subtipos de AVC cuja causa permanece obscura, não obstante investigação apropriada. Este desencorajante grupo de casos era antigamente tido como pouco frequente, provavelmente sem importância e tem toda a probabilidade de não causar um AVC incapacitante nem constituir um grande risco de recorrência. Nenhuma destas reconfortantes idéias foi corroborada e, em última análise, terá sido ao contrário. A severidade inicial do AVC é tão grande quanto o são os fatores de risco; o risco de recorrência neste grupo é quase tão alto como o associado com um fator de risco cardiaco óbvio, pará AVC embólico, e a severidade da recorrência é tão séria como nos de outras causas. O problema do tratamento destas situações é de que o risco de recorrência não é muito alto em qualquer dos grupos. Ele é até suficientemente baixo, de modo que redução clinicamente importante na taxa de recorrência com qualquer terapêutica põe sérios problemas no cálculo do tamanho da amostragem. Partindo do princípio de que se devem incluir num determinado estudo os doentes com risco de recorrência e lembrando-nos das limitações colocadas na maioria dos ensaios pelos austeros membros da maioria dos comitês institucionais de apreciação, bem como dos comitês dos direitos dos doentes, a probabilidade é de que os pacientes incluídos num determinado estudo tenham um déficit inicial ligeiro em relação a AVC hemisférico de causa desconhecida. Um grupo com risco de recorrência do AVC suficientemente baixo, de modo a apresentar uma reilução de $30 \%$ com um elevado grau de confiança no resultado do estudo, envolve cerca de 1900 doentes em cada ramo 47.

Têm sido obtidos poucos resultados em estudos clínicos de modo a satisfazer as expectativas de cada um e, por isso, ainda menos encantos desperta 0 fato de ensaios clínicos de pequenas dimensões não mostrarem benefícios da terapêutica, mesmo que esses efeitos existam.

O tema dos enfartes hemorrágicos merece alguns comentários. É conhecido de longa data o fato de que algum grau de enfarte hemorrágico seja comum depois de um AVC embólico e que esse evento não implica em que o vaso ocluído recanalize. Além disso, quantidades pequenas a moderadas de enfarte hemorrágico aparecem frequentemente como isodensas na TAC. Nestes casos também, a terapêutica com heparina não é perigosa. Nos AVC maciços a frequência de enfartes hemorrágicos sem anticoagulação é suficientemente elevada para fazer com que, em tais casos, o médico prudente evite seu uso. Poderá argumentar-se que a anticoagulação é útil quando se considera a possibilidade de recorrência do AVC, mas o ponto fundamental é que um enfarte maciço constitui suspeita suficiente de perspectivas graves para desencorajar qualquer idéia de anticoagulação. Como consequência, quando um enfarte é volumoso ou quando se vê na TAC imagem uniformemente hiperdensa, ou mesmo quando a imagem é heterogeneamente hiperdensa, parece não existirem razões suficientemente boas para planejar terapêtica com anticoagulantes. 


\section{REFERENCIAS}

1. Aaslid R - Transcranial Doppler Sonography. Springer, New York, 1986.

2. Aaslid R, Markwalde T-M, Nornes H - Noninvasive transcranial Doppler ultrasound recording of blood flow in basal cerebral arteries, $J$ Neurosurg 57:769, 1982.

3. Arders A - Neurosurgical Applications of Transcranial Doppler Sonography. Springer, New York, 1986 .

4. Awad AI, Carter LP, Spetzler RF, et al - Clinical vasospasm after subharacnoid hemorrhage: response to hypervolemic hemodilution and arterial hypertension. Stroke $18: 365,1986$.

5. Barnett HJM, Mohr JP, Stein BM, Yatsu FMI - Stroke: Pathophysiology, Diagnosis and Management. Churchill Livingstone, New York, 1968.

6. Baron JC, Bousser MG, Rey, et al - Reversal of focal «misery perfusion syndrome» by extra-intracranial arterial bypass in homodynamic cerebral ischemia. Stroke 12:454, 1981 .

7. Bradley WG Jr, Schmidt PG - Effects of methemoglobin formation on the MR appearance of subarachnoid hemurrhage. Radiology 156:99, 1985.

8. Brass LR, Prohovnik I, Pavlakis S, Mohr JP - Transcranial Doppler examination of middle cerebral artery velocity versus xenon rCBF: two measures of cerebral blood flow. Neurology 37 (suppl):85, 1987.

9. Comerota AJ, Cranley JJ, Cook SE - Real-time B-mode carotid imaging in diagnosis of cerebrovascular disease. Surgery 6:718, 1981.

10. Damasio H - A computed tomographic guide to the identification of cerebral vascular territories. Arch Neurol 40:138, 1985.

11. Delal PM, Shah PM, Aiyar RR - Arteriographic study of cerebral embolism. Lancet $2: 358,1965$.

12. Demeurisse M, Verhas M, Capon A, Paternot J - Lack of evolution of the cerebral blood flow during clinical recovery of a stroke. Stroke 14:77, 1983.

13. Donaldson RM, Emanuel RW, Eearl CJ - The role of two-dimensional echocardiography in the detection of potentially embolic intracardiac masses in patients with cerebral ischemia. J Neurol Neurosurg Psychiat 44:803, 1981.

14. Fisher CM, Gore I, Okabe N, White PD - Atherosclerosis of the carotid and vertebral arteries-extracranial and intracranial. $J$ Neuropath Exp Neurol 24:455, 1965.

15. Fisher CM, Ojemann RG - A clinico-pathologic study of carotid cndarterectomy plaques. Rev Neurol (Paris) 142:573, 1986.

16. Gilles $\mathcal{C}$, Brucher JM, Khoubesserian $P$, et al - Cerebral amyloid angiopathy as a cause of multiple intracerebral hemorrhage. Neurology 34:730, 1984.

17. Gomori JM, Grossman RI, Goldberg HI, et al - Intracranial hematomas: imaging by high-field MR. Radiology 157:87, 1985.

18. Gray $\mathbf{F}$, Dubas $\mathbf{F}$, Roullet $\mathbf{E}$, Escourolle $\mathbf{R}$ - Leukoencephalopathy in diffuse hemorrhagic cerebral amyloid angiopathy. Ann Neurol 18:54, 1985.

19. Gross CR, Kase CS, Mohr JP, Cunningham SC - Stroke in south Alabama: incidence and diagnostic features. Stroke $15: 249,1984$.

20. Harders A, Gilsbach J - Time course of blood velocity changes related to vasospasm in the circle of Willis measured by transcranial Doppler. J Neurosurg 66:718, 1987.

21. Harvey JR, Teague SM, Anderson JL, et al - Clinically silent atrial septal defects with evidence for cerebral embolization. Ann Int Med 105:695, 1986.

22. Heiss W-D (ed): Functional Mapping of the Brain in Vascular Disorders. Springer, Berlin, 1985.

23. Heiss W-D, Herholz $\mathbf{K}$, Boecher-Schwarz HG, et al: PET, CT, and MR imaging in cerebrovascular disease. J Comp Tomogr 10:903, 1986.

24. Hilal SK, Maudsley AA, Simon HE, et al - In vivo imaging of sodium-23 in the human head. J Comput Asst Tomog 9:1, 1985.

25. Hinton RC, Kistler JP, Fallon JT, et al - Influence of etiology of atrial fibrillation on incidence of systemic embolism. Am J Cardiol 40:509, 1977.

26. Hinton RC, Mohr JP, Ackerman RA, et al - Symptomatic middle cerebral artery stenosis. Ann Neurol 5:152, 1979.

27. Irino $T$, Tandea $M$, Minami $T$ - Angiographic manifestations in posrecanalized cerebral infarction. Neurology 27:471, 1977.

28. Jacobson HG (ed) - Fundamentals of magnetic resonance imaging. JAMA 258:3417, 1987.

29. Kase CS, Williams JP, Mohr JP - Lobar intracerebral hematomas. Neurology 32:1146, 1982. 
30. Kelcz F, Hilal SK, Hartwell P, Joseph PM - CT measurement of the xenon blood-brain partition coefficient and implications for rCBF: a preliminary report. Radiology $127: 385,1978$.

31. Kroener JM, Dorn PL, Shoor PM, et al - Prognosis of asymptomatic ulcerating carotid lesions. Arch Surg 115:1387, 1980.

32. Kunitz S, Gross CR, Heyman A, et al - The pilot stroke data bank: definition, design, data. Stroke 15:740, 1984.

33. Lassen $\mathrm{N}$, Ingvar $\mathrm{DH}$, SKinhoj $\mathrm{EL}$ - Brain function and blood flow. Scientific American $239: 62,1978$.

34. Lennihan L, Kupsky WJ, Mohr JP, et al - Lack of association between carotid plaque hematoma and ipsilateral cerebral symptoms. Stroke 18:879, 1987.

35. Levy DE, Scherer PB, Lapinski RH, et al - Predicting recovery from acute ischemic stroke using multiple clinical variables. In Plum F, Pulsinelli W (eas): Cerebrovascular Disorders, Raven Press, New York, 1985, pg 69.

36. Maudsley A, Hilal SK, Perman W, Simon H - Spatially resolved high resolution spectroscopy by «four dimensional» NMR. J lMagn Reson 51:147, 1983.

37. Melamed N, Satya-Murit S - Cerebellar hemorrhage. Arch Neurol 39:425, 1984.

38. Mohr JP - Neurologic complications of caraiac valvular disease and cardiac surgery. In Vinken PJ, Bruyn GW (eds): Handbook of Clinical Neurology, Vol. 34, IMedical Conditions. North Holland, Amsterdam, 1979, pg 143.

39. Mohr JP - Asymptomatic carotid artery disease. Stroke 13:431, 1982.

40. Mohr JP - Lacunes. Neurol Clin N Amer 1:201, 1983.

41. Mohr JP, Caplan LR, Melski JW, et al - The Harvard cooperative stroke registry: a prospective registry of cases hospitalized with stroke. Neurology 28:754, 1978.

42. Mohr JP, Rubenstein L, Edelstein SZ, et al - Approaches to pathophysiology of stroke through the NıNCDS Data Bank. In Plum F, Fuisinelli W (eds): Cerebrovascular Disorders, Raven Press, New York, 1985, pg 63.

43. Mokri B, Sundt TM Jr, Houser OW, Piepgras DG - Spontaneous dissection of the cervical internal carotid artery. Ann Neurol 19:126, 1986.

44. Norrving B, Nilsson B, Olsson J - Progression of carotid disease after endarterectomy: a Doppler ultrasound study. Ann Neurol 12:548, 1982.

45. Pessin MS, Duncan GW, Mohr JP, Poskanzer DC - Carotid artery territory transient ischemic attacks. N Eng J Med 296:358, 1977.

46. Pessin MS, Hinton RC, Davis KR, et al - Mechanisms of acute carotid stroke. Ann Neurol 6:245, 1979.

47. Petty GW, Lennihan L, Mohr JP, et al - Complications of long term anticoagulation. Ann Neurol 20:157, 1986.

48. Powers WJ, Press GA, Grubb R, et al - The effect of hemodynamically significant carotid artery disease on the hemodynamic status of the cerebral circulation. Ann Int Med 106:27, 1987.

49. Reuten GM - Ultrasonic Diagnosis of Cerebrovascular Diseases. Martinus Nijhoff, Dordrecht, 1987.

50. Roger LR, Cho E-S, Kempin J, Posner JL - Cerebral infarction from non-bacterial thrombotic endocarditis: clinical and pathological study including the effects of anticoagulation. Am J Med 83:746, 1987.

51. Sacco RL, Mohr JP, Tatemichi TK, et al - Reclassification of acute stroke with nondiagnostic computed tomography and angiogram: infarction of undetermined cause in the NINCDS Stroke Data Bank. Ann Neurol 20:156, 1986.

52. Sacco RL, Owen J, Tatemichi TK, Mohr JP - Protein S deficiency and intracranial vascular occlusion. Ann Neurol 22:115, 1987 (Abtr).

53. Sandercock P, Warlow C, Bamford J, et al - Is a controlled trial of long-term oral anticoagulants in patients with stroke and non-rheumatic atrial fibrillation worthwhile? Lancet 1:788, 1986.

54. Schwartz A, Hennerici $M$ - Noninvasive transcranial doppler ultrasound in intracranial angiomas. Neurology $36: 626,1986$.

55. Sipponen JT, Kaste M, Sepponen RE, et al - Nuclear magnetic resonance imaging in reversible cerebral ischaemia. Lancet 1:294, 1983.

56. Weaver RG Jr, Howard G, McKinney WM, et al - Comparison of Doppler ultrasonography with arteriography of the carotid bifurcation. Stroke 4:402, 1980.

57. Yatsu FM, Mohr JP - Anticoagulation therapy for cardiogenic emboli to brain. Neurology $32: 274,1982$.

58. Zwiebel WJ - Vascular Ultrasonography. Ed 2. Grune \& Stratton. New York, 1986. 